\title{
The outcome of hematopoietic stem cell transplantation patients with COVID-19 infection
}

\author{
Almetwaly M. Sultan $\mathbb{1}^{1} \cdot$ Hossam K. Mahmoud ${ }^{1,2} \cdot$ Gamaleldin Mohamed Fathy $^{1} \cdot$ Nabil M. Abdelfattah $\mathbb{D}^{1}$
}

Received: 6 August 2020 / Revised: 30 September 2020 / Accepted: 8 October 2020 / Published online: 4 November 2020

(c) The Author(s), under exclusive licence to Springer Nature Limited 2020

\section{To the Editor:}

Data concerning the impact of COVID-19 on hematopoietic stem cell transplant (HSCT) patients are scarce and variable. It is thought that HSCT patients may be at higher risk of COVID-19-associated complications secondary to immunosuppressive therapy, and the subsequent delayed immune reconstitution at the post-transplant phase [1].

In this report, we describe the clinical course of seven stem cell transplant recipients at the Nasser's Institute for Research and Treatment Hospital who survived a diagnosis of COVID-19. Patients were identified as being SARS-CoV-2 positive by real-time polymerase chain reaction. Nasopharyngeal swabs were performed in the context of symptoms (fever, cough, dyspnea, and fatigue), radiological findings, or contact with a documented SARS$\mathrm{CoV}-2$ positive individual. The median age of patients was 30 years (range, 3-43 years), two patients (28\%) were females and five $(72 \%)$ were males, and the median time from stem cell infusion to the diagnosis of COVID-19 was 8 months (range, 3-113 months).

All patients received allogeneic stem cell transplantation (allo-SCT) from human leukocyte antigen (HLA) 10/10matched related donors. All patients received myeloablative conditioning regimens. Four patients (66\%) received posttransplant cyclophosphamide (PTCy), and one patient received antithymocyte globulin rabbit for primary graftversus-host disease (GvHD) prophylaxis. None of our patients had a relapse at the point of being diagnosed with a

Almetwaly M. Sultan

almetwaly_sultan@yahoo.com

$\triangle$ Nabil M. Abdelfattah

nabil161289@gmail.com

1 Nasser's Institute for Research and Treatment Hospital, Cairo, Egypt

2 National Cancer Institute, Cairo, Egypt
COVID-19 infection. All patients were receiving immunosuppressant therapy at diagnosis, with a stable graft function before COVID-19 positivity. Immunosuppressants were continued after the diagnosis of COVID-19 was confirmed. All patients not previously receiving corticosteroids were given prednisone at a dose of $0.5 \mathrm{mg} / \mathrm{kg} / \mathrm{day}$ PO for 10 days $(0.4 \mathrm{mg} / \mathrm{kg} / \mathrm{day}$ methylprednisolone equivalent), azithromycin $500 \mathrm{mg} /$ day PO for 6 days $(10 \mathrm{mg} / \mathrm{kg} /$ day for pediatrics), voriconazole $200 \mathrm{mg}$ PO q12h for 1 month $(7 \mathrm{mg} / \mathrm{kg} / \mathrm{dose}$ $\mathrm{q} 12 \mathrm{~h}$ PO for pediatrics), and high-dose cotrimoxazole for PCP coverage $(15 \mathrm{mg} / \mathrm{kg} / \mathrm{day}$ trimethoprim PO for 2 weeks). Adult patients were given rivaroxaban $20 \mathrm{mg} /$ day $\mathrm{PO}$ according to their platelet counts for one month.

All patients were lymphopenic with a median absolute lymphocyte count of $0.76 \times 10^{9} / \mathrm{L}$ (range, $0.31-0.97 \times 10^{9} / \mathrm{L}$ ). The median platelet count was $115 \times 10^{9} / \mathrm{L}$ (range, $80-230 \times$ $10^{9} / \mathrm{L}$ ) at the diagnosis of COVID-19. Only one patient (14\%) had acute grade II GvHD of the skin and gut (overall grade II per Glucksberg criteria) and was receiving prednisone ( $2 \mathrm{mg} / \mathrm{kg} /$ day PO) and mycophenolate. Two patients had chronic GvHD of the skin and liver; one patient was receiving prednisone $1 \mathrm{mg} / \mathrm{kg} / \mathrm{day} \mathrm{PO}$, while the other patient was receiving cyclosporine, mycophenolate, and prednisone $(0.5 \mathrm{mg} / \mathrm{kg} / \mathrm{day} \mathrm{PO})$. Except for systemic corticosteroids, none of our patients received specific treatment for COVID19. Patients' characteristics and their outcome are summarized in Table 1.

Regarding COVID-19 symptoms, four patients (57\%) experienced mild lower respiratory tract symptoms, three (43\%) experienced high-grade fever, and all of them had chest infiltrates on both chest radiographs and computed tomography scans. The median follow-up was 82 days (range, 77-112) from the onset of COVID-19.

Our observations are inconsistent with those reported by Kanellopoulos et al., where they reported a mortality rate of $43 \%$. However, their patients' characteristics were different. The median age in their patient population was 61 years, half of the allo-SCT were HLA 10/10-matched unrelated donor transplants, two (34\%) had a haploidentical 


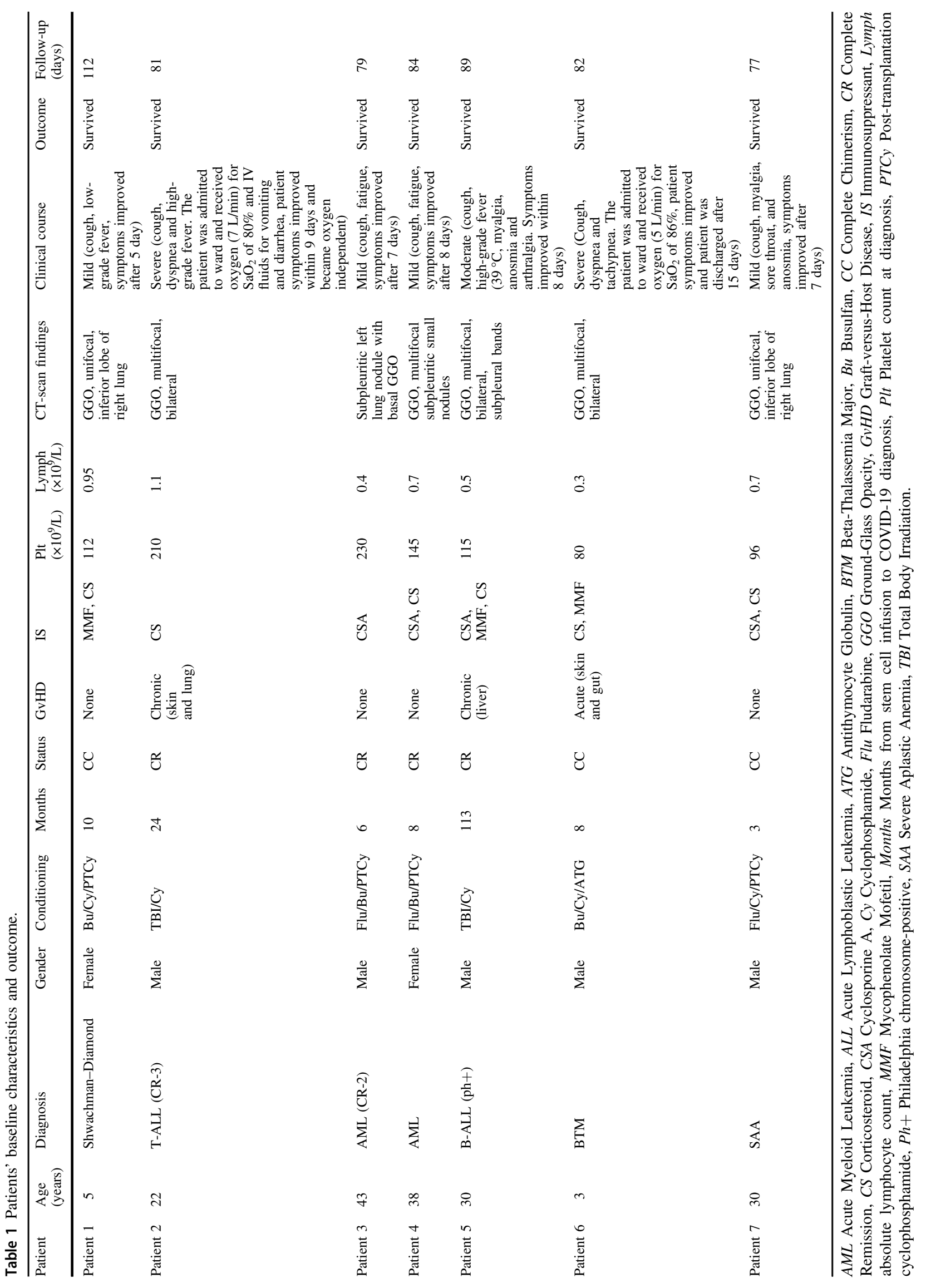


transplant, one (16\%) had an HLA 9/10-matched unrelated donor transplant, and no patient received a myeloablative allo-SCT. Of note, out of the three patients who received PTCy, only one patient (64 years) died due to CNS bleeding secondary to AML relapse [2].

Our observations also differ from those reported by Malard et al. from the hematology department of Saint Antoine hospital in Paris, where they reported $52 \%$ of their patients developed ARDS and a 1-month mortality rate of $40 \%$. Remarkably, only one out of three patients who received cyclophosphamide-based regimens died. Half of their patients were older than 65 years of age, and all patients who died were older than 65 years. This suggests that COVID-19 mortality risk factors in HSCT patients may be similar to those in the general population [3].

We propose a few remarks for consideration. First, despite receiving myeloablative conditioning regimens, we had no mortality among our patients secondary to COVID-19. Second, we observed that all patients who received PTCy for GvHD prophylaxis experienced mild COVID-19 symptoms. Cytokine release syndrome (CRS) that is frequently associated with haploidentical HSCT and mitigated by PTCy- shares similar pathophysiology with severe COVID-19-associated CRS [4, 5]. We hypothesize that PTCy might have a protective role against COVID-19associated CRS.

We recommend controlled studies with a greater number of patients and longer follow up periods-with special attention to the impact of cyclophosphamide on COVID-19 outcome-to reach a definite conclusion concerning the outcome of COVID-19 in HSCT.

\section{Compliance with ethical standards}

Conflict of interest The authors declare that they have no conflict of interest.

Publisher's note Springer Nature remains neutral with regard to jurisdictional claims in published maps and institutional affiliations.

\section{References}

1. Ogonek J, Juric MK, Ghimire S, Varanasi PR, Holler E, Greinix H, et al. Immune reconstitution after allogeneic hematopoietic stem cell transplantation. Front Immunol. 2016;7:507.

2. Kanellopoulos A, Ahmed MZ, Kishore B, Lovell R, Horgan C, Paneesha S, et al. COVID-19 in bone marrow transplant recipients: reflecting on a single centre experience. Br J Haematol. 2020;190: e67-70.

3. Malard F, Genthon A, Brissot E, van de Wyngaert Z, Marjanovic Z, Ikhlef $S$, et al. COVID-19 outcomes in patients with hematologic disease. Bone Marrow Transplant. 2020;55:2180-4. https://doi.org/ 10.1038/s41409-020-0931-4.

4. Abboud R, Keller J, Slade M, DiPersio JF, Westervelt P, Rettig $\mathrm{MP}$, et al. Severe cytokine-release syndrome after $\mathrm{T}$ cell-replete peripheral blood haploidentical donor transplantation is associated with poor survival and anti-IL-6 therapy is safe and well tolerated. Biol Blood Marrow Transplant. 2016;22:1851-60. https://doi.org/ 10.1016/j.bbmt.2016.06.010.

5. Moore JB, June CH. Cytokine release syndrome in severe COVID-19. Science 2020;368:473-4. 